\title{
La construcción de la mentalidad democrática como necesidad en el posconflicto ${ }^{1}$
}

\section{The construction of democratic mentality as necessity in post-conflict}

Daniel Alfonso Barragán Ronderos ${ }^{2}$

Fecha de recepción: 25 de enero de 2016

Fecha de aprobación: 7 de marzo de 2016

\section{RESUMEN}

El presente artículo, en primera instancia, suscita un recorrido histórico frente al conflicto armado en Colombia y llega a la comprensión de las causas que han generado la situación de violencia en el país.

Se presenta, en segunda instancia, una mentalidad democrática abierta al diálogo y la disertación, como pieza clave de la cultura política a construirse como proceso educativo e ilustrado, dando cabida al advenimiento de una pedagogía política, fundamental para la renovación del pensamiento colombiano y la solución de conflictos.

De las dos instancias mencionadas surge el proyecto político-pedagógico de la construcción de la mentalidad democrática como factor que preserve la democracia y realice conjuntamente la construcción del Estado nacional.

1 El artículo es producto del proyecto de investigación institucional "LA CONSTRUCCIÓN DEMOCRÁTICA INMERSA EN LA CONSTITUCIÓN DE 1991", el cual es financiado por la Universidad La Gran Colombia. El citado proyecto de investigación está vinculado al Grupo de Investigación "Teoría del Derecho, la justicia y la política" de la citada Universidad.

2 Politólogo - Universidad Nacional de Colombia. Especialista en Edumática - Universidad Autónoma de Colombia. Magíster en Filosofía Latinoamericana - Universidad Santo Tomás de Aquino. Docente e Investigador - Universidad La Gran Colombia. Correo Electrónico: daniel.barragan@ugc.edu.co 
En definitiva, el artículo es una propuesta del proyecto de construcción de la mentalidad democrática en el país.

Palabras clave: escenarios del posconflicto, mentalidad democrática, proyecto políticopedagógico, ilustración política, acuerdos de paz, diálogos en La Habana.

\section{Abstract}

This article, in the first instance, raises a historical tour against the armed conflict in Colombia, reaching the understanding of the causes that have generated the violence in the country.

Is presented, in the second instance, a fundamental condition for the renewal of the Colombian thought democratic mentality open to dialogue and discourse, as ey part of the political culture to be built as an educational and illustrated process, allowing for the advent of a political pedagogy, and conflict resolution.

Of the two instances mentioned political-pedagogical project of building democratic mentality as a factor that preserves democracy and jointly perform the construction of the national state arises.

In short, the article is a project proposal of building the democratic mentality in the country.

Keywords: Post-conflict scenarios, democratic mentality, politics and education, political enlightenment, peace agreements, dialogues in Havana 


\section{INTRODUCCIÓN}

La metodología del presente artículo se inscribe dentro de un seguimiento documental de las principales obras de Enrique Dussel y Daniel Herrera Restrepo, al sumar algunos análisis pertinentes a la normatividad inmersa en la construcción democrática de la sociedad civil.

Se fundamenta en la teoría social o teoría de la acción, que se determina bajo presunciones concretas (sujetas a un determinado contexto), y son la guía para contribuir a un tipo de estudio fundamental, que incluye tanto comportamientos observables como los significados e interpretaciones que dicha práctica lleva asociadas para quienes la realizan, como sucede en este proyecto de investigación.

Se trata de una perspectiva de investigación que centra su interés en analizar y controlar cómo se producen los procesos de cambio que tienen lugar en las prácticas investigativas:

"Este proceso de investigación es promovido por los propios sujetos que llevan a cabo dichas prácticas, de ahí que se hable de investigación en la acción” (Martínez, 2007, p.33), considerando que el dinamismo se enmarca desde diversas esferas, cuya proposición es la estructuración y comprensión de la sociedad.

La secuencia lógica de la investigación lleva un diseño metodológico, que se incorpora en la discusión y debate teórico, y consolida las estrategias de recolección, análisis y argumentación de la información documental propia del proyecto.

En el escenario de la investigación teórica, desarrollada en esta investigación, se articula la teoría de la liberación de Enrique Dussel y la Fenomenología del profesor Daniel Herrera, en cuanto a su comprensión de la democracia, haciendo un análisis de la percepción individual y social de la verdadera comunidad.

El arraigo de las metodologías empleadas en Latinoamérica proporciona una visión desde la filosofía naciente de dicha región, que aporte perspectivas innovadoras de investigación, a través del pensamiento que surge de esa zona. 
En esencia, el trabajo comprende la variedad y riqueza de nuestro propio pensamiento y enmarca sus postulados teóricos en las orientaciones de la filosofía política de Dussel y Herrera, como exponentes latinoamericanos, para el análisis del neoconstitucionalismo en la región. Específicamente, en el desarrollo de la Constitución Política de 1991 en Colombia.

En el análisis de la normatividad inmersa en la construcción democrática en Colombia, se analizarán cada uno de los artículos sobresalientes, en cuanto a las temáticas de participación ciudadana y desarrollo de la sociedad civil, de la Constitución Política de 1991, que representa el tenor de la discusión legal acerca de la inclusión democrática de los ciudadanos, en la construcción democrática de la sociedad civil.

La comparación de la normatividad, su estudio y análisis generarán nuevas interpretaciones al desarrollo legislativo y jurisprudencial, que al respecto de la construcción democrática establece el sistema político de la Constitución de 1991.

\section{ANTECEDENTES}

Según Sánchez (1991), Colombia es un país que ha atravesado una larga trayectoria de guerra endémica permanente que se extiende hasta nuestros días. En su misma constitución como República, atraviesa 14 años de Guerra de Independencia contra el régimen colonial español y, durante el resto del siglo XIX, vive "ocho guerras civiles generales, catorce guerras civiles locales, dos guerras internacionales con Ecuador y tres golpes de cuartel". En el siglo XX, además de una guerra con el Perú, se encuentra el período conocido como "La Violencia", atribuida a la lucha bipartidista, y durante la cual se originan movimientos insurgentes, que posteriormente llegan a conformar guerrillas. A este escenario se suman numerosos levantamientos populares y sociales, la organización de grupos paramilitares, la influencia del narcotráfico y la ayuda militar extranjera, dando lugar a un complejo panorama de conflicto armado y creciente militarización en el país.

Las primeras décadas del siglo XX estuvieron marcadas por numerosas huelgas obreras y levantamientos campesinos, puesto que no existían legislaciones laborales ni agrarias 
para normalizar las relaciones; las condiciones de trabajo estaban caracterizadas por extensas jornadas, salarios miserables y ausencia de seguridad social, mientras en los campos era frecuente la expropiación de tierras.

Uno de los casos más paradigmáticos es el de la masacre de las bananeras en 1928, ocurrida en la región de Ciénaga, Magdalena, por parte de la empresa estadounidense United Fruit Company, y denunciada por Jorge Eliécer Gaitán Ayala. Sin embargo, en estos levantamientos populares es necesario reconocer la influencia de la Revolución Mexicana, con la cual se hizo conocida la consigna "la tierra es de quien la trabaja"3, así como del triunfo del proletariado con la Revolución de Octubre en Rusia 1917; en 1926 se creó el Partido Socialista Revolucionario que dio origen al Partido Comunista Colombiano.

En 1930, los liberales llegan nuevamente a la Presidencia y permanecen allí durante un período de 16 años. En 1946, a causa de divisiones internas del partido, son lanzados dos candidatos, Gabriel Turbay y Jorge Eliécer Gaitán, lo cual conduce a la pérdida del poder para el partido liberal y el triunfo de los conservadores con Mariano Ospina Pérez, quien gana las elecciones presidenciales. Aunque dicho Gobierno se inició con promesas de una "Unión Nacional” entre los dos partidos, al poco tiempo empezó el despido de trabajadores liberales para colocar conservadores en su lugar; el cuerpo policial no fue la excepción y constituye un caso emblemático, puesto que parte importante de sus nuevos integrantes fueron sicarios reclutados en la región norte de Boyacá y llegaron a conocerse como la policía "chulavita”, encargada de sembrar el terror entre la población liberal en distintas zonas del país mediante masacres oficiales (Pecaut, 1987) ${ }^{4}$. Con ello se inició "la Violencia”, término con el cual se ha denominado el período de guerra bipartidista entre, aproximadamente, 1946 y $1953^{5}$.

3 Esta frase es retomada por Jorge Eliécer Gaitán quien abogaba por la necesidad de una reforma agraria e inspiró a sectores campesinos en su lucha por recuperar las tierras.

4 Pecaut, Daniel. (1987). Orden y violencia. Evolución socio-política en Colombia entre 1930 y 1955. Bogotá: Norma.

5 La duración de la etapa denominada "La Violencia” varía según distintos autores. Algunos como Gonzalo Sánchez la catalogan como un período de conmoción social y política comprendido entre 1945 y 1965. 
Desde inicios del siglo XX la intervención y presión extranjera, sobretodo de Estados Unidos de América, había influido en el conflicto interno colombiano, generando una pugna de intereses; la separación de Panamá y la masacre de las bananeras son algunos ejemplos ya mencionados. Sin embargo, hacia la mitad del siglo, fue relevante la situación que se presentó pasada la Segunda Guerra Mundial e iniciada la Guerra Fría.

En 1948, Bogotá fue elegida como sede de la Novena Conferencia Panamericana, dirigida por el General Marshall de Estados Unidos, buscando consolidar la colaboración entre los países americanos para fortalecer la seguridad y combatir un enemigo común: el comunismo. En el contexto de dicha reunión estalló el "Bogotazo" a raíz del asesinato de Jorge Eliécer Gaitán el 9 de abril del mismo año; el General Marshall atribuyó los sucesos a la acción comunista, mientras las masas gaitanistas liberales buscaban tomarse el poder. Si bien los dirigentes de los partidos Liberal y Conservador retomaron el acuerdo de "Unión Nacional" para calmar la situación, no se lograron detener las disputas locales; en zonas como el Tolima y Barrancabermeja se crearon juntas revolucionarias que amenazaron la autoridad conservadora.

En 1949, las crecientes tensiones bipartidistas condujeron a la disolución del acuerdo de Unión Nacional y a una serie de acontecimientos como el cierre del congreso por parte de Ospina Pérez y la elección de Laureano Gómez como presidente a pesar de que los liberales se habían abstenido de votar. Como lo expresa Pecaut (1987), ante la pérdida de legitimidad a causa de tales hechos, el poder sólo podía "sostenerse por la fuerza” (p. 526) ${ }^{6}$. La violencia se agudizó a tal punto que la única alternativa para gran cantidad de obreros ${ }^{7}$ y campesinos fue armarse e internarse en las selvas para salvaguardarse, dando lugar a organizaciones de autodefensa campesina liberales y comunistas, mientras los miembros de la dirección liberal se exiliaron en el exterior.

6 Pecaut, Daniel. 1987. Orden y violencia. Evolución socio-política en Colombia entre 1930 y 1955. Bogotá: Norma. 526

7 En 1948 se prohibieron las huelgas y tuvieron lugar despidos masivos. Juntas militares eran las encargadas de juzgar a los insurgentes liberales y comunistas, haciendo que el conflicto se extendiera al campo. 
Durante "la Violencia", el principal actor armado oficial encargado de la situación de orden público fue la policía, aunque con la ayuda de 'parapolicías', cuerpos civiles armados dirigidos por los conservadores entre los cuales se cuentan los 'chulavitas' de Boyacá y los 'pájaros', que operaron en el Valle del Cauca y Caldas. El papel del ejército era más modesto en términos políticos y el estamento militar se encontraba subordinado al poder civil de los partidos, de modo que el pueblo depositó sobre este la esperanza de restablecer el orden. Ello explica el alto nivel de aceptación entre liberales y conservadores frente al golpe militar por parte del general Rojas Pinilla el 13 de junio de 1953.

Rojas Pinilla ordenó el cese de hostilidades contra los grupos insurgentes y decretó una amnistía, logrando la desmovilización de varias columnas guerrilleras que no buscaban el combate revolucionario sino la defensa ante la persecución, entre ellas la del llano a cargo de Guadalupe Salcedo. Sin embargo, las autodefensas comunistas no creyeron en la amnistía pues sabían de las traiciones del Gobierno y se replegaron en zonas del sur del Tolima y Huila y conformaron las "Repúblicas Independientes". $\mathrm{Al}$ poco tiempo, varios exlíderes guerrilleros, como Salcedo, fueron asesinados y se inició la ofensiva contra los grupos que no se habían entregado. Del mismo modo, hubo represión de movilizaciones estudiantiles y el Partido Comunista Colombiano fue declarado ilegal en 1955.

Estos y otra serie de incidentes generaron descontento entre la población, a lo cual se sumó el inconformismo de los dirigentes de ambos partidos por las tendencias populistas de Rojas. Estos líderes se reunieron en Espańa para pactar la reconciliación entre los partidos y una repartición del poder; allí nació el Frente Nacional. En 1957, Rojas fue reemplazado por una junta militar y se realizó un plebiscito mediante el cual fue aceptada la propuesta del Frente Nacional: alternar las Presidencias entre liberales y conservadores, a la vez que distribuir los cargos públicos entre miembros de ambos partidos. El primer presidente fue el liberal Alberto Lleras Camargo desde 1958 hasta 1962.

Iniciado el Frente Nacional se dio el triunfo de la Revolución Cubana en 1959, sirviendo de inspiración al movimiento estudiantil, luego de lo cual se llegan a conformar el Movimiento Obrero Estudiantil de Colombia y el Ejército de 
Liberación Nacional, retomando ideas de Ernesto Che Guevara. Sin embargo, este suceso también alertó aún más a Estados Unidos sobre la amenaza del comunismo y la revolución en América Latina, lo que justificó la necesidad de difundir la ideología de seguridad nacional. En Colombia, la lucha bipartidista había menguado, pero apareció un nuevo "enemigo interno" que cuestionaba el sistema, lo cual dio paso a la consolidación de la Doctrina de Seguridad Nacional en el país. Se estrecharon los vínculos entre los Ejércitos de Colombia y Estados Unidos con acuerdos para el préstamo o la venta de equipos militares y un trabajo político e ideológico con el fin de reforzar la seguridad interna. Asimismo se desarrolló un plan de seguridad conocido como el "Plan Lazo" que obedecía a un modelo de guerra de baja intensidad.

En 1964, durante el Gobierno de Guillermo León Valencia, el Ejército adelantó acciones militares contra las "Repúblicas Independientes". A raíz de ello, estas autodefensas campesinas se replegaron y conformaron las Fuerzas Armadas Revolucionarias de Colombia (FARC), una guerrilla de orientación marxista leninista. A su vez, la aparición de nuevas guerrillas condujo a un reforzamiento de las acciones militares. El presidente emitió el decreto 3398 de $1965^{\circ}$, mediante el cual se estableció la defensa civil bajo el control militar y se autorizó el entrenamiento marcial de autodefensas en sectores rurales, dando lugar a los primeros grupos paramilitares dependientes del Ejército nacional. Asimismo, se recurrió al estado de sitio que permitió el juzgamiento de civiles por tribunales militares.

Una década más tarde se robusteció el empoderamiento del estamento militar mediante la inauguración del "Estatuto de Seguridad" durante el Gobierno de Julio Cesar Turbay. Con esta medida se inició un proceso represivo contra sindicalistas y miembros de organizaciones populares considerados de izquierda, caracterizado por detenciones indiscriminadas, torturas y desapariciones, denominado "guerra sucia”. En el código penal de 1980 se introduce por primera vez la tipificación como "terrorista", con lo cual se buscó restarle el carácter político a los diversos movimientos de oposición. De este modo, la opinión pública tendió a polarizarse entre quienes estaban a favor o en contra de las acciones militares.

8 La ley 48 de 1968, emitida por el presidente Carlos Lleras Restrepo, dio un carácter permanente al decreto 3398 de 1965 . 
De otro lado, el presidente Belisario Betancur, inspirado en las iniciativas de diálogo como salida al conflicto en otras partes de Latinoamérica, emprendió un proceso de paz con los distintos grupos insurgentes. En 1982, promulgó una amnistía y ordenó el cese de actividades militares contra las guerrillas; al año siguiente empezaron las negociaciones con las FARC y el M-199. Sin embargo, esto significó la reducción de la autonomía y protagonismo militar, lo cual generó descontento entre la institución castrense y sectores de extrema derecha. Buscaron sabotear el proceso de paz mediante la realización de operativos militares y paramilitares que dieron lugar a enfrentamientos armados. Esto, a su vez, condujo al M-19 a romper los acuerdos de paz y reanudar las acciones armadas, siendo la toma del Palacio de Justicia su máxima expresión, ante lo cual los militares tuvieron la "oportunidad de acabar con el último aliento pacificador" de Betancur.

No obstante, durante los diálogos con las FARC se había gestado la idea de crear un movimiento social y político en el cual tuvieran cabida las diversas propuestas de paz del pueblo colombiano y que retomara la participación electoral. De esta manera, nació la Unión Patriótica (UP) en 1985, un partido político con el apoyo de varios actores sociales (grupos guerrilleros, comunistas, liberales, sindicatos, estudiantes, campesinos, indígenas entre otros) que deseaban hallar una salida negociada al conflicto armado en Colombia en un marco de legalidad. La propuesta gozó de gran acogida: para las elecciones de 1986 son elegidos 14 congresistas, 18 diputados, y 335 concejales. El candidato presidencial de ese grupo, Jaime Pardo Leal, alcanza la votación más alta lograda por un partido independiente en la historia del país.

Por esta época, también había cobrado fuerza otro actor que permeó los distintos sectores sociales y aportó al recrudecimiento de la violencia: el narcotráfico. La grandes masas de dinero movilizadas por concepto de drogas dio lugar al surgimiento de nuevas élites, y estas necesitaban seguridad para sus negocios. Asíllegaron a ejercer gran influencia en la esfera política, ya fuera mediante soborno o sembrando terror, y lograron desarticular la rama judicial. A las guerrillas y sectores rurales también llegó su influencia; numerosas regiones donde se sembraba la coca se encontraban

9 Este grupo se formó a raíz de las elecciones de 19 de abril de 1970 en las cuales se consideró que mediante fraude electoral Misael Pastrana 'robó' las elecciones a Rojas Pinilla. 
bajo el control de estos grupos y se tradujo en beneficios económicos, lo cual hizo posible el refuerzo militar y la ampliación de sus frentes. Esto a su vez, se tradujo en la financiación de grupos paramilitares por parte de familias vinculadas al narcotráfico, quienes buscaban liberarse de las extorsiones guerrilleras; uno de estos movimientos se denominó Muerte A Secuestradores (MAS). Por su lado, los militares resultaron involucrados al permitir el buen funcionamiento de las exportaciones de droga en determinadas regiones y dar vía libre a la acciones de limpieza por parte de los sicarios en la zona.

Durante la Presidencia de Virgilio Barco, se intensificó la "guerra sucia" y el conflicto de baja intensidad, impulsado por los capos del narcotráfico, los grupos paramilitares y sectores de extrema derecha, extendiéndose hasta el Gobierno de César Gaviria. Se elaboró un plan de exterminio contra integrantes, familiares y simpatizantes de la UP, denominado el 'Baile Rojo', que dejó entre 1985 y 1993 un saldo de 1163 ejecuciones extrajudiciales (entre ellas los dos candidatos presidenciales Jaime Pardo Leal y Bernardo Jaramillo-Ossa) y 123 desapariciones forzadas. El narcotráfico cobró múltiples víctimas entre ellas la de Guillermo Cano (director del diario El Espectador) y Luis Carlos Galán (candidato presidencial del Nuevo Liberalismo), y sembró el terror a través de bombas en lugares como los edificios de El Espectador y, el DAS y en un avión de Avianca.

No obstante, en marzo de 1990 se logró la desmovilización del M-19 luego de haberse pactado la creación de una Asamblea Nacional Constituyente, requisito exigido por el grupo insurgente. Se conformó el movimiento político Alianza Democrática M-19 y lanzaron a Carlos Pizarro Leongómez como candidato presidencial para las elecciones de 1990. El 26 de abril del mismo año fue asesinado en un avión.

La década de los noventa inició con grandes expectativas frente a la Asamblea Nacional Constituyente, en la cual participaron diversos sectores de la sociedad y dio lugar a la Constitución de 1991. Sin embargo, con ello no se neutralizó a los diversos actores del conflicto; los paramilitares desplazaron al ejército en el control de varias regiones del país y la Presidencia de Ernesto Samper se vio involucrada en un escándalo por respaldo económico del narcotráfico. 
En 1998, el presidente Pastrana abrió nuevamente un diálogo de paz con las guerrillas, particularmente con las FARC, mediante la desmilitarización de varios municipios colombianos y con la promesa de reconocerles un estatus político. En medio de dicho proceso, las disputas entre guerrilla y paramilitares parecieron agudizarse y la sociedad civil quedó atrapada entre los distintos actores armados en sus zonas de influencia, lo que generó numerosos desplazamientos de la población. La problemática alcanzó tales magnitudes que se convirtió en un tema internacional, representando una amenaza a países vecinos como Venezuela y Ecuador. En cuanto al tráfico de drogas, en 1999 se comenzó la ejecución del Plan Colombia, un proyecto de cooperación bilateral entre los Gobiernos colombiano y estadounidense para combatir el narcotráfico y el terrorismo por parte de grupos al margen de la ley, mediante el fortalecimiento y modernización de la Fuerza Pública; con ello se pretendía reactivar la economía y conseguir la paz en Colombia.

El año 2001 marca un punto crítico en la caracterización del conflicto armado colombiano. Por una parte, se pone en marcha la destrucción de cultivos ilícitos, principal fuente de financiación de los grupos paramilitares y guerrilleros, y la modernización de las fuerzas armadas; esto evidentemente pone en riesgo las negociaciones. Por otra, los atentados sufridos en Estados Unidos el 11 de septiembre sirvieron de trampolín para impulsar una lucha contra un nuevo enemigo internacional: el terrorismo. De este modo, el conflicto colombiano fue transferido a la categoría de terrorismo internacional. En febrero de 2002, se rompen los diálogos con la guerrilla.

\section{Constitución política de 1991 y el acercamiento}

\section{a una mentalidad democrática}

Con la expedición y vigencia de la Constitución Política de 1991, se instauraron mecanismos de participación ciudadana que posibilitan la construcción democrática de la sociedad civil, la unidad nacional y la inclusión de la población que históricamente había sido excluida por el sistema político. 
La Carta Constitucional colombiana abre la posibilidad de la participación ciudadana a todos los sectores de la sociedad civil, que representan el conglomerado total de los habitantes del territorio.

Aunque no se trata de la panacea, incluye la primera oportunidad de acercarse a la construcción de la mentalidad democrática en Colombia, necesaria para desarrollar por primera vez una política nacional propia sin la intromisión de agentes externos a la sociedad.

La mentalidad democrática es un concepto argumentado por el profesor Herrera (2002) para intentar describir cómo los antiguos griegos basaron su Democracia en la virtud de la ciudadanía y en el cumplimiento del mandato soberano del pueblo. Este es retomado a lo largo de la presente investigación para llegar al valor teórico de la construcción de la mentalidad democrática en Colombia a partir de la Constitución de 1991, lo cual se explica en los aspectos metodológicos y se desarrolla en la argumentación sobre la mentalidad democrática inmersa en el orden constitucional a continuación.

\section{Mentalidad democrática inmersa en el orden constitucional}

El profesor Herrera (2002) se plantea el objetivo de esclarecer el concepto de democracia en cuanto a "la creación de una mentalidad democrática en todos los ciudadanos como presupuesto indispensable para la existencia de una sociedad democrática” (p. 90). Todo en pro de una verdadera vivencia fundamentada e intencionada para la apropiación democrática del mundo de la vida.

En cuanto a este esclarecimiento, el concepto de democracia se presenta múltiple (equívoco), puesto que no es suficiente la definición de "soberanía popular", sino que existen variables al concepto que lo adentran en una percepción oscura. Las democracias de tipo liberal, burguesa, socialista, participativa, subsidiada, entre otras, convierten el concepto en una amplia gama de sentidos y significados implícitos en diversas sociedades. 
En el camino del esclarecimiento, se recurre a ir a las cosas mismas. Allí se dejan a un lado las ideologías y se va a "la intencionalidad no realizada ni realizable plenamente; ante el proyecto que un pueblo -el griego- se dio un día, y que, posteriormente, fue asumido por todos aquellos que nos reconocemos culturalmente herederos de sus ideales" (Herrera, 2002, p. 91). Esto nos lleva al sentido de comunidad en su posible ser, de acuerdo con lo que debería ser la convivencia humana y su práctica colectiva. Es la referencia a la democracia, al salirse de su percepción organizativa del Estado y al llegar a su sentido como mentalidad vivencial cotidiana en la cual se centra un "ethos", un modo de ser en comunidad, por el cual se guía la experiencia humana.

Considerando que la democracia no se impone (como en un decreto) sino que se construye a diario, llegando a acuerdos que posibiliten la convivencia entre los distintos, la percepción que hace el profesor Herrera nos permite configurar una democracia creada desde abajo, por todos en común-unidad y no concibiendo a la democracia como la forma efectiva de un gobierno.

Para hallar una verdadera democracia, se inducen ciertos presupuestos que se complementan entre sí. Primero, la verdad no es "la conformidad del pensamiento con lo que es, ha sido y será eternamente. La verdad es encuentro y diálogo" (Herrera, 2002, p. 92), y, allí, el sentido de constante crítica al estado de cosas que no se establece por las autoridades supremas tradicionales, sino que en el acuerdo hablado llega la inclusión real de todos en común-unidad. Es una verdad desde la praxis humana, en plena comunicación e interrelación subjetiva, llegando a la objetividad propia y clara del concepto.

La democracia, como verdad en construcción, es aquel "ideal de vida social y política que un día el pueblo griego inicio dentro de su horizonte histórico vital" (Herrera, 2002, p. 92). Un ideal a futuro que desde el presente se halla como utópico, pero que en definitiva es realizable en la construcción comunal de una sociedad de derechos, sin el quebranto o flagelo de los gobiernos violentos sobre sus espaldas.

Cuando se presenta el ejercicio del poder de manera violenta para parcializar, dividir y despolitizar a la comunidad, en "apariencia” se logra más poder sobre la sociedad (autoritarismo, totalitarismo). 


\begin{abstract}
"Pero en realidad en estos casos disminuye el poder de la comunidad, porque se aísla a los miembros del todo político; la comunidad pierde poder y el gobernante también pierde fuerza (en tanto que no puede ejercer delegadamente dicho poder para desarrollar la vida de la comunidad o defenderse de ataques externos), y da pasos al uso de la coacción sin consensos" (Dussel, 2009, p. 150).
\end{abstract}

El poder político se identifica con el consensual-comunicativo desde el doble movimiento para su ejercicio legítimo. Así se establece que el poder delegadoinstitucionalizado (potentia) deviene de la "potestas", que es la acción comunal, de la convocatoria a la asamblea constituyente para conformar una constitución.

Estos delegados en un bloque histórico se presentan como la clase dirigente que en alianza con los demás grupos sociales y en hegemonía respetuosa de las minorías, ejercen un poder político de acuerdo con la voluntad y razón política de todos en la comunidad de forma combinada y en pro de su beneficio.

La propuesta se observa en la siguiente afirmación: "el poder consensual institucionalizado como poder político ejercido delegadamente por un gobierno, en tanto poder político fundado en la Potentia, cobra así la fisonomía del poder político hegemónico" (Dussel, 2009, p. 93). Todo esto nos lleva a afirmar que la construcción democrática deviene del acuerdo y no de la imposición, algo en lo que se complementan las posturas de Herrera y Dussel.

Así configurando un circulo virtuoso, entre estos autores, se amplia de lo concreto a lo comunal universal la percepción de la democracia, al comprenderse como el modo de ser persona en sociedad; una sociedad en construcción por el compromiso democrático de sus individuos. Lleva de esta forma a la democracia y su modo de ser persona a la experiencia de los valores, sin los cuales no se tendrían raíces para sostener una vida democrática.

Todo apunta a que "no se puede ser demócrata cuando no se ha experimentado el valor de la solidaridad, del altruismo, de la responsabilidad social, del espíritu cívico, del respeto por los bienes comunes y ante todo el respeto por la persona humana” 
(Dussel, 2009, p. 93). Aquí se enmarca un compromiso ético para la construcción de la democracia, en el establecimiento de un sentido social de común-unidad para el avance de todos, sin llegar a discursos de mayorías excluyentes.

Así se llega al principal cuestionamiento por resolver: ¿Cómo construir democracia en un país desde siempre intervenido, descuartizado y criado por la violencia ideológica?

Lo cual tiene una primera respuesta al finalizar la década de 1980, cuando llega cierta reacción hacia la tan necesaria construcción democrática (aunque aún medida por intereses particulares) cuando inmersos en la crisis del narcotráfico (en todos los ámbitos) se hizo posible llegar a la constituyente.

Con la Constitución de 1991 se llega al triunfo de la pluralidad de sujetos autónomos como gestores de su propia historia. Es la edificación desde el derecho de un proyecto de vida político, hacia la ética de un sistema político nacido enfermo. Es la aproximación al ser intersubjetivo, una democracia que se nos presenta no solo como estructura estatal sino como proyecto de autorrealización de los sujetos, en un Estado como momento de la sociedad civil, no como una propiedad privada, sino como colectivo en el salvamento de la vida en la democracia. Todo en el establecimiento de la participación como figura clave de la intersubjetividad.

En el plano de la realización del individuo se contempla el sistema de las necesidades entendido por Hegel (1968), en su obra "La Filosofía del Derecho", en la tercera parte sobre la ética, en la sección sobre la sociedad civil, en cuanto el hombre entra en una sociedad para satisfacer mejor sus necesidades. Implicando la consecución de un trabajo, con el cual, engrane en el sistema social, colaborando con la totalidad social y retribuyéndosele su esfuerzo. Lo cual hace relevante al trabajo en la definición de un individuo en su identidad.

Ese sistema social del trabajo de Colombia presenta en la actualidad dificultades por fenómenos como el desempleo o la insatisfacción que produce un empleo por obligación, como lo explica Herrera (2002) en su texto sobre "el derecho al trabajo". 
En ese texto, presenta la insatisfacción en el trabajo de un individuo, explicándolo a través de la siguiente analogía:

\begin{abstract}
"A quien se le niegue la posibilidad de experimentar el verdadero sentido del trabajo revivirá en su existencia el mito de Sísifo, del Sísifo que experimentó su existencia como la de un ser condenado a arrastrar diariamente una piedra hasta lo alto de una montańa para dejarla rodar y comenzar de nuevo a arrástrala, indefinidamente hasta su muerte" (Herrera, 2002, p. 165).
\end{abstract}

En la obra de Herrera se genera una convicción del verdadero sentido del trabajo, donde éste entrama "la posibilidad de realizar nuestro deber ser, la posibilidad de vivir realmente la intersubjetividad, la posibilidad de crear o recrear un mundo que sea digno de la dignidad humana" (Herrera, 2002, p. 165). Con lo cual, se podría acercar la percepción normativa ideal de la persona, con el postulado del verdadero sentido del trabajo, puesto que con base en el cumplimiento ético de su ideal el ser humano llega a realizarse.

Se afirma que las preguntas éticas que realiza el individuo poseen imperativos incondicionados que aluden a la elección por la cual el individuo decide el camino de una profesión donde pueda ayudar a alguien, implicando una inserción en el sistema social del trabajo para contribuir en la construcción de la sociedad. Pero existen fenómenos que hacen que la intención del individuo quede obstaculizada o no se llegue a cumplir. En este caso, se presenta una visión de acuerdo a la escala de valores del individuo y una visión de acuerdo al interés de alcanzar su ideal primario en su proyecto de vida. Que se entiende, de acuerdo con la ética clásica aristotélica, como caminos que conducen a la vida buena y a la felicidad.

En cuanto a la vida como derecho, se presenta como irrenunciable, el más respetable y defendible de los fundamentos humanos, con el que se inscriben las habilidades de cada individuo hacia la construcción intersubjetiva de la sociedad.

Con vida y trabajo digno, el proyecto político de la democracia es posible y perdurable para nuestra común-unidad vitalizada en el esfuerzo cotidiano. 
Si se llega al principio democrático que propone Dussel (2006) en su tesis décima, en cuanto al consenso legítimo que se haya en la comunidad, podemos comprender cómo existe una complementariedad entre el pensamiento fenomenológico de Herrera y la ética política de Dussel, de acuerdo con que el proyecto político se construye desde abajo, con cada persona en su interrelación con los demás, hacia la democracia como utopía futura trabajada desde el presente.

Comunidad incluyente que depara un proyecto político de todos, democracia como institucionalización de la intersubjetividad, que en dialogo construye realidad, y que fomenta la transformación gradual de situaciones catastróficas a las que nos han llevado la sucesión de egoísmos y malas administraciones en el poder.

De esta forma, la necesidad de una Política de la liberación en Colombia se presenta en la dignificación de la vida de todos los ciudadanos, de la liberación de la sociedad en el cumplimiento del proyecto de la democracia.

El proyecto de la liberación iniciaría en la eliminación de la corrupción en la administración pública a través de la ética como fundamento de la construcción política del Estado. Todo aquel que se presente como funcionario deberá considerar el bienestar colectivo antes que el individual, so pena de ser marginado de la sociedad con graves penas establecidas jurídicamente.

Es volver más estricto el control del Estado, para que no se repitan hechos funestos como los ocurridos en la administración del exalcalde de Bogotá Samuel Moreno Rojas, que en su cartel de la contratación despilfarraron el erario público e hirieron de muerte el progreso que la capital venía teniendo en las anteriores administraciones.

En cuanto al desarrollo de la arquitectura de la política de la liberación, en Colombia se hace necesario que la participación política pase de ser una actividad temporal (cada vez que se realizan elecciones) a que sea una actividad continúa.

Es el engranaje de la sociedad a la toma de las decisiones que afectan a todos, es la posibilidad de establecer un Gobierno que comprometa a la ciudadanía en la 
gestión, ejecución y evaluación de las políticas púbicas como ocurre en los países desarrollados.

Es un chequeo y balance de la razón administrativa, en el que no se privilegien los intereses personales sino que el colectivo surja victorioso ante la intervención de Estado en los diferentes niveles, desde el barrio, la comunidad, la localidad, el municipio, el departamento, hasta llegar a cubrir la totalidad de la nación.

Es el compromiso de acercar la política a la población, que sintiéndose perteneciente a un proyecto ético-político de la liberación, haga sustentable un desarrollo estatal alternativo al impuesto por los intereses internacionales sobre nuestro territorio.

Es replantear las políticas dañinas a la población y posibilitar la emergencia de un estado de cosas nuevo, hacia la prosperidad que tanto requiere un pueblo vibrante y ansioso de encontrar el camino hacia la paz. Considerando que uno de los principales inconvenientes que el país ha tenido a lo largo de su historia es el fenómeno de la violencia, el planteamiento de la teoría de la liberación como base de una construcción política desde la alteridad podría servir para buscar la posibilidad de la paz.

Si comprendemos que el conflicto surge como consecuencia de la desigualdad, entre la oligarquía y ciertos sectores extremistas, podemos descifrar la raíz misma de la guerra interna y tratar de encontrar un camino hacia el dialogo y la necesaria paz.

En cuanto al desarrollo económico de la sociedad, al ser este uno de los países más ricos en recursos hídricos, biodiversidad, minerales, fértiles tierras de cultivo y un excelente capital humano, solo se debería consolidar un consenso para el progreso, una unión entre todas las regiones, entre todos los talentos, para que el nivel de vida alcance los del mundo desarrollado.

No es la construcción descentralizada y egoísta que ha hecho que cada región observe su porvenir de acuerdo con sus recursos y capacidad administrativa, sino en un trabajo conjunto con la colaboración de todos, para un fin común, dentro de una gran nación, establecer los parámetros para solventar los principales problemas que afectan a todas las regiones. 
Solo obsérvese el caso europeo, que ha respondido a las crisis de todos sus integrantes, sin que se produzcan proyectos de exclusión, como se plantean en esta patria, dejando a su suerte a muchos de los departamentos más necesitados.

\section{Conclusiones}

El proyecto ético-político de la liberación se consolidaría en una coherente política educativa para el progreso social, que sería la base de una mentalidad democrática, en la cual no exista la posibilidad de la exclusión y en la que se garantice que las nuevas generaciones refuercen el desarrollo alcanzado por una comunidad que ha comprendido su papel en el mundo, ha logrado concretar su identidad y su sentido de pertenencia por el país.

Entrando en lo discursivo político hacia el consenso autónomo, libre y soberano se puede llegar al principio democrático. Ese principio material del ejercicio de la razón política.

Se define el reconocimiento como aquel acto de la razón, en el que inmiscuido con la política se interpreta como el conocer al otro como igual. Es el doble movimiento, de no solo quedarse a conocer que es el otro sino aceptar e interiorizar que la esencia de ese otro, no es lo ajeno que me resulte, sino la persona que existe y se presenta como mi igual.

En el nivel social el reconocimiento es aquello que lleva al hombre en común-unidad a mantener afecto por los miembros pares de su cotidianidad. Es esa voluntad elevada al nivel de la comunicación que hace posible compartir el mundo con el otro en una relación fraternal que se encuentra forjada en la posibilidad de la convivencia pacífica.

No es la negación de la diversidad ni la homogeneización de la sociedad para pacificar. Es la construcción en consenso de una realidad basada en la diferencia y su reconocimiento en completo respeto y común entendimiento de la igualdad que nos convoca a todos y que va más allá de la piel oscura o clara que los hombres y mujeres tengan para contener su espíritu. 
Así se dan las pautas para un consenso legítimo que lleve al hombre a una sociedad incluyente y justa, en la que todos conformamos una común-unidad, sin mayorías opresoras, minorías absolutas o patriarcados culturales. Todos serían sinónimo de democracia en sentido estricto.

Se insta a la comprensión del principio democrático como acercamiento a la noción de mandar obedeciendo, de acuerdo con la estrategia del poder que se institucionaliza en la decisión de la autoridad ("potestas") por conformar un cuerpo especializado para el ejercicio de la política y el poder, que conlleva un consenso generalizado a favor de un tipo de gobierno en el cual la obligación se presenta como propio respeto de la palabra dada en la configuración social.

Con la democracia no se incentiva el individualismo liberal que dominó el modernismo, es el paso que se consolidó en la creación de una mentalidad común para el respeto y la inclusión de todos. Es comprender a la sociedad como la unión que cobra más fuerza y vigencia entre más compacta se halle. Así se encuentra el espacio de confrontación entre ideología individualista e intersubjetividad comunicacional, responsable, dinámica y en movimiento dialógico hacia la verdadera comunicación política que lleve a la decisión que instaura el consenso de todos.

Es ese poder anterior al constituyente, aquel instituyente que se instaura en el consenso y que se reaviva en la unión.

Frente a la crisis de lo institucionalizado, el principio democrático emerge como la forma en la que el pueblo vuelve a crear consenso, aquel fundamento primero que encausa un acto hacia lo político.

Es el primero de los principios que fundamenta la vida en comunidad y que se instaura en la raíz primera de cualquier común unidad hacia la conformación de lo social.

En la práctica de la democracia aparece la intersubjetividad actual que lleva a una cultura política que interrelaciona las escuelas de cuadros de los partidos políticos, los medios de comunicación y los testimonios de una vida en igualdad, que entrevé 
la difusión y la crítica democrática. Se presenta el encuentro entre sinónimos del principio democrático con el principio de la legitimidad política, generándose un encuentro entre iguales percepciones del origen esencial del poder político, ese acto que divide la historia de la prehistoria en la organización social. Todo de acuerdo a la consideración de que el consenso es factor de lo político.

En la voluntad de participación se encuentra el respeto al acuerdo alcanzado en el consenso. Esa aceptación del otro como compañero que hace parte de la comunidad.

\section{REFERENCIAS}

Dussel, E. (2006). 20 tesis de politica. México: CREFAL. Siglo XXI Editores.

Dussel, E. (2009). Politica de la liberación. T.2. Arquitectónica. Madrid: Editorial TROTTA.

Hegel, G. F. (1968). La Filosofia del Derecho. Buenos Aires: Editorial Claridad.

Herrera, D. (2002). La persona y el mundo de su experiencia. Bogotá: Universidad de San Buenaventura.

Martínez, R.A. (2007). La investigación en la práctica educativa: guia metodológica de investigación para el diagnóstico y evaluación en los centros docentes. Bogotá: Ministerio de Educación Nacional.

Pecaut, D. (1987). Orden y violencia. Evolución socio-politica en Colombia entre 1930 y 1955. Bogotá: Norma.

Sánchez, G. (1991). Los Estudios sobre la Violencia en Colombia, Balance y Perspectivas. En: Sánchez, G. y Peñaranda R. (comp.). Pasado y Presente de la Violencia en Colombia. Bogotá: CEREC. 